\title{
FORMULATION DEVELOPMENT AND CHARACTERIZATION OF GELUCIRE BEADS OF ANTIHYPERTENSIVE DRUG FOR FLOATING DRUG DELIVERY SYSTEM USING $3^{2}$ FACTORIAL DESIGNS
}

\author{
KHUSHBOO RANKA*, KAMAL S RATHORE \\ Department of Pharmacy, B.N. University, Udaipur, Rajasthan, India. Email: ranka.khushboo0@gmail.com \\ Received: 17 December 2020, Revised and Accepted: 22 January 2021
}

\begin{abstract}
Objective: The aim of this study was to design and to optimize lipid based beads for multiunit floating drug delivery of ramipril.

Methods: The beads prepared by melt-solidification method. In the investigation $3^{2}$ full factorial design was used to investigate the joint influence of two formulation variable amount of Gelucire (X1) and Tween 20 (X2) as independent variable and the percentage drug release in 1 (Y1), 6 (Y2), and $12 \mathrm{~h}$ (Y3) as dependent variable. Gelucire 43/01 has chosen for release retardant and Tween 20 for solubility enhancement and drug loading agent.

Results: The results of multiple linear regression analysis indicated that for obtain a floating drug delivery, the optimum concentrations of both the lipid and drug loading agent should be used. The factorial models were used to prepare optimized floating beads and optimized formulations showed controlled release profiles for the extended period of more than $12 \mathrm{~h}$.
\end{abstract}

Conclusion: From the study, it was concluded that beads of Gelucire for sparingly water-soluble drug ramipril can provide controlled release for extended period.

Keywords: Floating drug delivery system, Gelucire, Ramipril, Tween 20, Solubility Enhancement, Percentage drug release, Factorial design.

(C) 2021 The Authors. Published by Innovare Academic Sciences Pvt Ltd. This is an open access article under the CC BY license (http://creativecommons.org/ licenses/by/4.0/) DOI: http://dx.doi.org/10.22159/ajpcr.2021v14i3.40352. Journal homepage: https://innovareacademics.in/journals/index.php/ajpcr

\section{INTRODUCTION}

Oral delivery is the favored path for the administration of drugs due to with its ease of use, low cost, and high compliance with patients. Some drawbacks related to quick gastric emptying time and low bioavailability of certain drugs due to incomplete absorption and degradation in the gastrointestinal tract (GIT) have been demonstrated by most conventional oral drug delivery systems [1]. To overcome this complication, controlled drug delivery system is designed to improve the pharmacological activity of a therapeutic agent or active pharmaceutical ingredients by increasing the drug solubility, bioavailability, stability, reducing side effects, and enhancing the selective delivery of drug with a predictable rate and mechanism [2]. The gastroretentive drug delivery system is one novel approach in this field. Dosage forms that can be retained in the stomach for prolong period of time are called gastroretentive drug delivery system [3]. Numerous approaches to gastroretentive drug delivery such as high density systems (i.e., retained in the bottom of the stomach [4]), low-density systems (reason for buoyancy in gastric fluid [5-7], mucoadhesive systems (which causes bioadhesion to stomach mucosa [8]), unfoldable, extendible or swellable systems (which limits emptying of the dosage forms through the pyloric sphincter of stomach) $[9,10]$, and superporous hydrogel systems [11] and magnetic system have been design and developed [12].

Buoyancy in gastric fluid, floating system (dynamically controlled) allows it to float over contents of gastric and stay floating in stomach without impacting the gastric transit time [13].

Various types of polymers used to formulate floating drug delivery systems are designed to distribute drugs to particular regions in the GIT [14]. Much focus has recently been on the use of fats and fatty acids as carriers in drug delivery systems in which Gelucire is one of the preferred excipients [15,16,].
Gelucire is derived from mono, di, and triglyceride mixtures of polyethylene glycol fatty acid esters [17]. Different types of Gelucire can be identified by two digits, where the first and second digit signifies the melting point of the base and the hydrophilic-lipophilic balance (HLB) value of water to fat soluble parts in each Gelucire, respectively. The melting point of Gelucire has a variance of $33-65^{\circ} \mathrm{C}$ and HLB variance of 1-14. Hence, if we consider Gelucire 43/01, 43 would be the melting point, and 1 its HLB [18].

Ramipril is an inhibitor of the long-acting non-sulfhydryl angiotensin converting enzyme (ACE) that was developed about a decade ago for clinical use. Ramipril is a drug which is de-esterifies to form ramiprilat, its active metabolite, in the liver [19]. It is an extremely lipophilic active antihypertensive medication ( $\log \mathrm{p}=3.32$ ), a poorly water-soluble drug with $28-35 \%$ absolute bioavailability [20]. In the earlier, mildto-moderate essential hypertension in $85 \%$ of patients was effectively treated with ramipril 2.5 or $5 \mathrm{mg} /$ day. Hence, it is a useful alternative for ACE inhibitor where positive effect of the drug was seen in patients who had heart failure, post-acute myocardial infarction, shows clinical studies. So far, patients with established asymptomatic left ventricular dysfunction (or heart failure), it is safe to assume, ramipril will be worth it [21].

\section{MATERIALS AND METHODS}

Materials

Drug (Ramipril), Tween 20, Span 80, and dimethyl sulfoxide (DMSO) were obtained as a gift sample from Emcure Pharmaceutical Limited Pune, India. Gelucire43/01, Gelucire 50/13, and Gelucire 48/16 were obtained as a gift sample from Gattefosse India Pvt. Ltd, Mumbai, India. All other chemicals used were of analytical grade.

\section{Drug-excipient compatibility study}

Fourier-transform infrared (FTIR) spectroscopy was carried out to check the compatibility between drug and polymer. The spectra of drug 
with polymers were compared with the standard spectrum of the pure drug [22].

\section{FTIR analysis}

Pure drug and physical mixtures between $400 \mathrm{~cm}^{1}$ and $4000^{-1} \mathrm{~cm}$ have been performed with the infrared spectroscopy.

\section{Ultraviolet (uv) scan of ramipril}

$\lambda_{\max }$ required to prepare calibration curve was derived by performing a scan using UV spectrophotometer between 200 and $400 \mathrm{~nm}$. For this, a drug sample concentrated at $10 \mu \mathrm{g} / \mathrm{ml}$ was used.

\section{Calibration curve of Ramipril in $0.1 \mathrm{~N} \mathrm{HCl}$}

A standard plot of the drug was prepared in $0.1 \mathrm{~N} \mathrm{HCl}$ to determine the drug content of ramipril. Stock solution of the ramipril having concentration of $100 \mu \mathrm{g} / \mathrm{ml}$ was prepared and diluted serially to attain a concentration range between 5 and $30 \mu \mathrm{g} / \mathrm{ml}$. These were spectrophotometrically analyzed using UV spectrophotometers at 210 $\mathrm{nm}$.

\section{Preparation of Gelucire beads}

Lipid (Gelucire) has melted to $50^{\circ} \mathrm{C}$ and gradually the fine powdered drug has been added to form dispersion with the uniform mixture. The resulting dispersion was dropped to $100 \mathrm{ml}$ Prechilled $\left(4^{\circ} \mathrm{C}\right)$ water at a rate of $5 \mathrm{drop} / \mathrm{min}$ through 23 -guage syringe needle $(0.65$ $\mathrm{mm}$ inner diameter). The distance between the tip of the needle and water was $5 \mathrm{~cm}$ in $100 \mathrm{rpm}$ with the magnetic stirrer for $15 \mathrm{~min}$, the contents were stirred. The beads were then collected through a Whatman filter paper (\#41), 3 times washed with distilled water and then dried up in the vacuum desiccator for duration of $24 \mathrm{~h}$ to ensure that the solvents had been completely removed. Beads for their weight were measured every $6 \mathrm{~h}$. Separated and combined for dispersion medium are used in a number of other vehicles such as olive oil, light liquid paraffin, ethanol, isopropyl myristate, coconut oil, and isopropyl alcohol [23].

\section{Preliminary screening of lipid carrier and dispersing media}

To assess three different grades of lipid, the preliminary screening was carried out as a carrier- Gelucire 48/16, Gelucire 50/13, and Gelucire $43 / 01$ using various drug-to-carrier ratio $(1: 10,1: 20,1: 30$, and 1:40) in various vehicles such as water, olive oil, light liquid paraffin, ethanol, isopropyl myristate, coconut oil and isopropyl alcohol separately, and in combination ratio were used as dispersion medium.

Optimization of Gelucire $43 / 01$ beads using a $3^{2}$ factorial experimental design with Drug loading agent concentration

To evaluate the collective effect of Gelucire 43/01 and Tween 20 on the drug release from the beads a full factorial design was used. Factorial experiments $3 \mathrm{n}$ ( $\mathrm{n}$ factors each at three levels) is of historical interest and software's are usually used to analyze the outcome of factorial experiments. Ramipril-Gelucire beads were prepared using a $3^{2}$ factorial experimental design in order to investigate the main effects as well as interaction of formulation and process variables using Design Expert $^{\circledR}$ software (8.0.6). In this design, two factors are evaluated, each at three levels and experimental trials are performed at all nine possible combinations. For this study, the formulation variables were Gelucire 43/01 concentration (X1) and Tween 20 (X2). The percent drug released after 1 (Y1), after 6 (Y2), and after 12 h (Y3) was selected as the dependent variables. Tables 1 and 2 illustrate the composition of the prepared beads. A statistical model incorporating interactive and polynomial terms that correlate the independent variables and response is described by Equation (1);

$Y=b_{0}+b_{1} X_{1}+b_{2} X_{2}+b_{12} X_{1} X_{2}+b_{11} X_{1} X_{1}+b_{22} X_{2} X_{2}$

Where $b_{0}$ is the arithmetic mean response of the 9 runs; $b_{1}$ and $b_{2}$ are the estimated coefficients for $X_{1}$ and $X_{2}$, respectively; and $b_{12}$ is the estimated coefficients for interaction terms $\left(\mathrm{X}_{1} \mathrm{X}_{2}\right)$. The model used for main effects of the variables $X_{1}$ and $X_{2}$ represent the changing variable each at a time. The second-order interaction $\left(\mathrm{X}_{1} \mathrm{X}_{2}\right)$ shows that how the value of $X_{1}$ amplifies or downplays the effect on the response of a change in $X_{2}$. The polynomial terms were included to investigate nonlinearity [24].

\section{Morphology study (scanning electron microscopy [SEM])}

SEM used to study the surface morphology and inner textures of the optimized formulation.

\section{In vitro drug release study}

Using USP paddle type II dissolution apparatus, the release of ramipril from the floating beads was determined. In the dissolution apparatus, a weighted amount of beads equal to $5 \mathrm{mg}$ of drug was place in $900 \mathrm{ml}$ of $0.1 \mathrm{~N} \mathrm{HCl}(\mathrm{pH} \mathrm{2.0)}$ dissolution media. At a rotation Speed of $50 \mathrm{rpm}$, the dissolution media were held at $37 \pm 0.5^{\circ} \mathrm{C}$. During the analysis of drug release, optimal sink conditions maintained for that $5 \mathrm{ml}$ samples were removed at every $1 \mathrm{~h}$, passed through a membrane filter and the initial volume of the dissolution media was preserved by adding $5 \mathrm{ml}$ of fresh dissolution fluid after each removal. Using a UV-Visible spectrophotometer at $210 \mathrm{~nm} \lambda$, samples were analyzed. The release profile of marketed formulation, that is, conventional tablet of ramipril (Ramgee-5, German Remedies Pharmaceuticals pvt. Itd) was also determined by the same procedures as followed earlier [25].

\section{In vitro drug release kinetics}

The release kinetic was studied by various kinetic models as zero-order, first-order, Higuchi model, and Korsmeyer-Peppas equation. The value of correlation coefficient $\left(R^{2}\right)$ nearly 1 , verified the most suitable model.

The zero-order model describes where the drug is released independent of its concentration and is commonly identified as the matrix based drug with low solubility. Information obtained from drug releases in vitro has been obtained as percentage cumulative drug releases verses time to know correlation coefficient.

The first-order equation describes the systems in which releases depended on the concentration of the drug and is commonly identified as water-soluble drugs in the porous matrix. The data obtained were plotted as log cumulative percentage of drug retained verses time.

The Model Higuchi model is based on Fickian diffusion that explains the drug's release of an insoluble matrix linearly linked to the square root of time. Graph between cumulative percentages drug released and root square of time was obtained.

Table 1: Factorial $3^{2}$ design to optimize Ramipril-Gelucire Beads

\begin{tabular}{llll}
\hline Factors & \multicolumn{3}{c}{ Level used } \\
\hline Independent variables & -1 & 0 & 1 \\
& 200 & 250 & 300 \\
Gelucire 43/01 (mg) & 0.2 & 0.4 & 0.6 \\
Tween20 (\%) & &
\end{tabular}

Table 2: $3^{2}$ factorial design layouts and their responses

\begin{tabular}{llllll}
\hline $\begin{array}{l}\text { Formulation } \\
\text { code }\end{array}$ & \multicolumn{2}{l}{$\begin{array}{l}\text { Variable level in } \\
\text { coded form }\end{array}$} & \multicolumn{3}{l}{$\begin{array}{l}\text { Responses } \\
\text { (Dependent Variables) }\end{array}$} \\
\cline { 2 - 6 } & $\mathbf{X 1}$ & $\mathbf{X 2}$ & Y1 & Y2 & Y3 \\
\hline A1 & -1 & -1 & 20.764 & 60.573 & 97.472 \\
A2 & -1 & 0 & 23.021 & 66.234 & 98.04 \\
A3 & -1 & 1 & 27.536 & 71.905 & 99.171 \\
A4 & 0 & -1 & 18.507 & 58.262 & 91.786 \\
A5 & 0 & 0 & 21.329 & 61.124 & 95.745 \\
A6 & 0 & 1 & 25.278 & 67.911 & 96.322 \\
A7 & 1 & -1 & 13.429 & 49.212 & 80.435 \\
A8 & 1 & 0 & 15.122 & 52.616 & 85.547 \\
A9 & 1 & 1 & 19.072 & 56.573 & 87.817 \\
\hline$*$ Meanyyyyyyyyy
\end{tabular}


Korsmeyer-Peppas equations can further analyze the dissolution data to verify the release model. Data obtained in in vitro drug release studies were collected as a log cumulative percentage release of drugs versus log time to find out the mechanism of drug release kinetics.

The $\mathrm{n}$ value is used to characterize drug release mechanism if $\mathrm{n}$ value formulation is $0.45<\mathrm{n}$ corresponds to a Fickian diffusion mechanism (case I), $0.45<\mathrm{n}<0.89$ to non-Fickian transport (anomalous), and $\mathrm{n}>0.89$ to super Case II transport (relaxational) [26].

\section{RESULTS AND DISCUSSION}

\section{FTIR spectrum}

The spectrum of ramipril and physical mixture of ramipril with Gelucire 43/01 was obtained by using FTIR (Figs. 1 and 2). The graph of ramipril showed distinctive peaks at $747.97 \mathrm{~cm}^{-1}$ (aromatic ring), $1181 \mathrm{~cm}^{-1}$ (C-O ester), $1646.08 \mathrm{~cm}^{-1}$ (C-O stretching), and $2806 \mathrm{~cm}^{-1}$ (C-H stretching). When we mix drug with excipient, 1102 and 1736 are common peak showed and are seen in respective IR. Therefore, there is no interaction among drug and excipient.

\section{UV scan of ramipril}

$\lambda_{\text {max }}$ of ramipril was found to be $210 \mathrm{~nm}$ in $0.1 \mathrm{~N} \mathrm{HCl}$. The calibration curve obtained in $0.1 \mathrm{~N} \mathrm{HCl}$ was a straight line and the calibration equation was found to be $y=0.0319 x+0.0322$ with $R^{2}$ of 0.9967 . This was used for the determination of concentration of unknown samples (Fig. 3).

\section{Preparation of Gelucire beads}

Gelucire 48/16 beads were prepared as dispersing media with tailing effect with light liquid paraffin; beads were not formed while using IPA, water, and other dispersing media. The beads were unable to retard the release of the drug after $4 \mathrm{~h}$. The drug was completely released within $4 \mathrm{~h}$. It, therefore, follows that these grades of Gelucire can be used as a method of drug delivery for fast release. The beads formed with Gelucire 50/13 and prechilled water as dispersing media; beads were not formed when using IPA and light liquid paraffin. During preparation, it was found to sink so that it affects the formulation's percentage yield and drug content. Gelucire 43/01 beads prepared with prechilled water as dispersing media, beads were not formed with other oils and organic solvents. Uniform and compact beads were found to float for more than $12 \mathrm{~h}$ and to retard the release of the drug depending on the amount of Gelucire 43/01 (Fig. 4). Prechilled water is used as surface active agent and cross-linking agent so might be these properties play an important role in uniform beads formation.

Further from the result of screening study, Gelucire 43/01 was chosen as release retardant for preparation of floating beads. Different drug and Gelucire 43/01 ratio $(1: 10,1: 20,1: 30,1: 40,1: 50,1: 60,1: 70$, and 1:80),

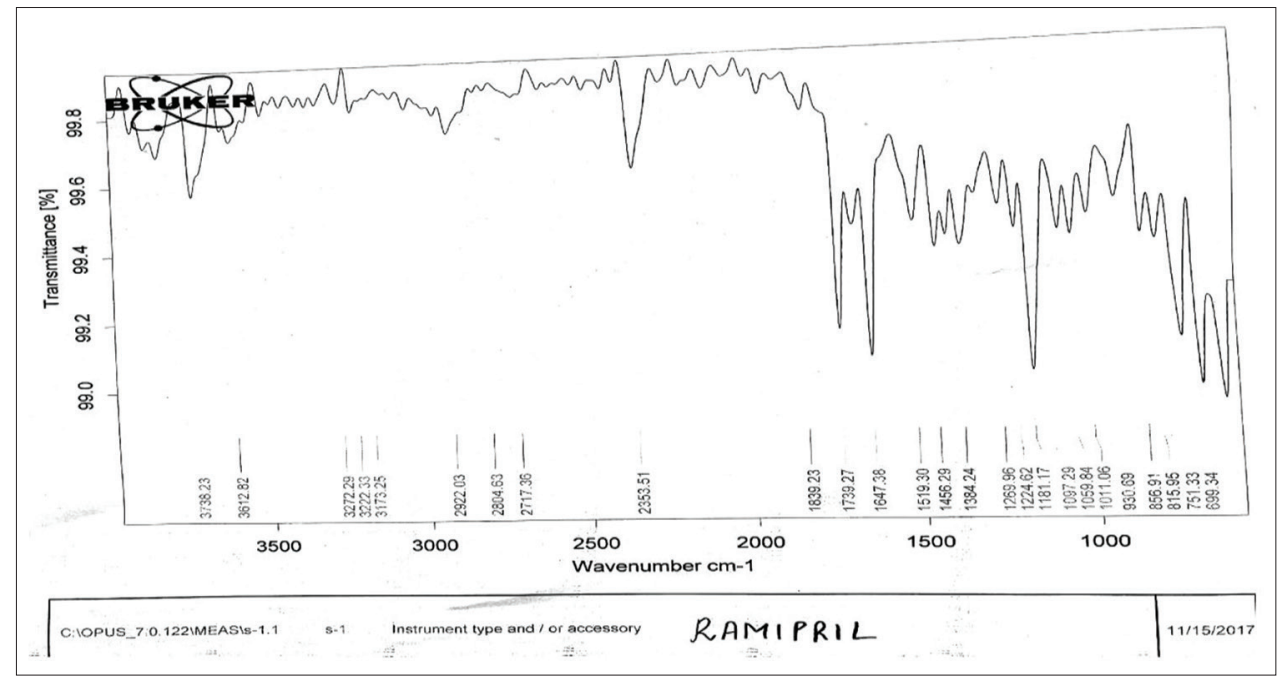

Fig. 1: Fourier-transform infrared of ramipril

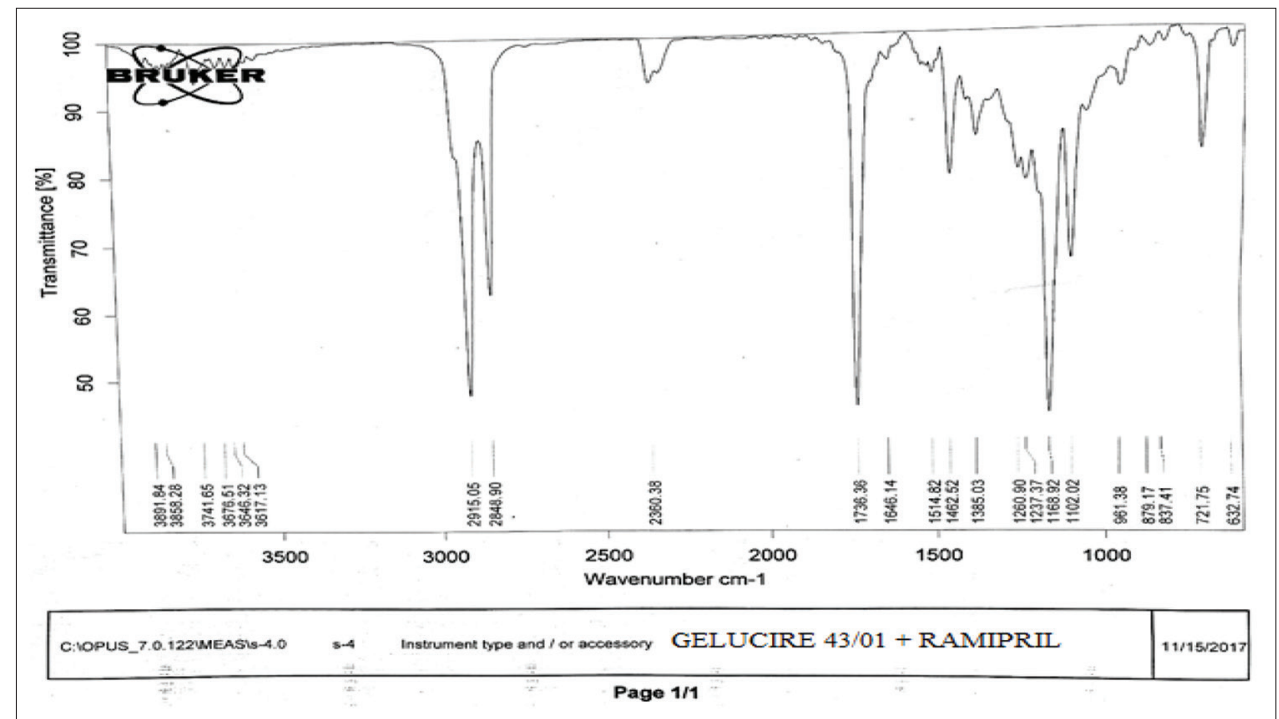

Fig. 2: Fourier-transform infrared of Ramipril + Gelucire 43/01 
prechilled water as dispersing media were prepared and evaluated for their \%Yield , \% Drug content, and \% floating for the optimization of Gelucire concentration. The obtained result indicated that increasing lipid concentration, increases \% yield $(47.23 \pm 0.52 \%$ to $92.12 \pm 0.95 \%)$ and $\%$ drug content $(15.1 \pm 1.02 \%$ to $73.1 \pm 1.23 \%)$ of the beads. There was no significant effect on percentage yield and percent drug content on increasing the lipid concentration beyond $300 \mathrm{mg}$. The \% floating (96-100\%) of all prepared beads was good, so it was concluded that increasing lipid concentration did not effect on \% floating. The fact that drug content was below $100 \%$ for all batches may also be due to the solubility of ramipril in water at the time of preparation before solidification of beads.

From the above result, it can conclude that $(1: 40,1: 50$, and $1: 60)$ formulation was the optimized formulation. To increases drug

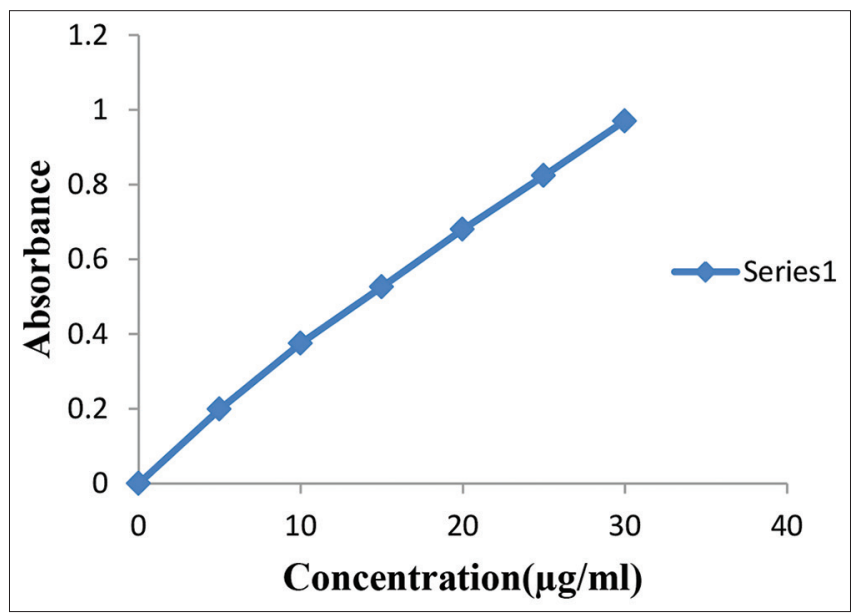

Fig. 3: Calibration curve of ramipril in $0.1 \mathrm{~N} \mathrm{HCl}$ content in batches drug loading agent (DMSO, Tween 20 and Span 80 , respectively) were added separately. It was, therefore, concluded that the addition of the drug loading agent in the formula did not substantially affect the percentage yield of beads. Percentage yield was good for all the prepared batches but increases \% drug content and solubility with Tween 20 .

Consequently, A three-level, two-factor factorial design was used to evaluate the combined influence of Gelucire 43/01 (X1) and Tween 20 (X2) as independent variable and the percentage drug release in 1 (Y1), 6 (Y2), and $12 \mathrm{~h}$ (Y3) as dependent variables.

\section{SEM of few beads}

SEM photograph of optimize formulation showed (Fig. 5) that beads had a spherical shape with the smooth perforated surface. The outer surface of beads was seen to be smooth, compact, and less porous, while the internal surface was highly porous. The less porous outside surface of the float beads and very porous inner surface assisted float on the GI content and controlled release of drugs.

\section{In vitro drug release}

To illustrate drug release profiles, in vitro dissolution data were adapted to various equations and kinetic models (Table 3, Figs. 6-9). The correlation coefficient $\left(\mathrm{R}^{2}\right)$ of each of the kinetics was measured and compared. The in vitro dissolution profiles of all the various floating bead formulations did not really match the actions of zero order and could best be represented by Higuchi's drug release equation. The initial fast release was due to the dissolution and diffusion of beads from the surface. As per Korsmeyer's equation, the data were further processed. The slope (n) values obtained by this equation showed that non-Fickian diffusion, that is, coupled diffusion and polymer matrix relaxation, controlled the release [23].

\section{Factorial design layout optimization}

The response data of 09 batches (A1 to A9) for drug release in 1, 6, and $12 \mathrm{~h}$ were fed to design expert software. A result of ANOVA for Response

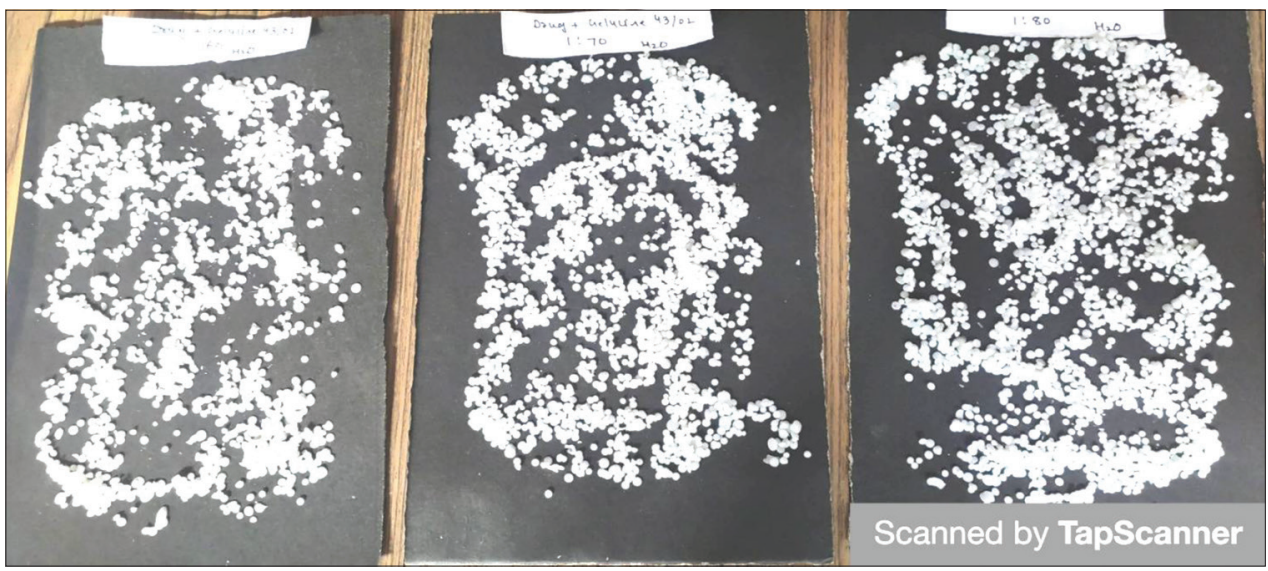

Fig. 4: Prepared beads

Table 3: Various kinetic models for Gelucire beads of ramipril

\begin{tabular}{|c|c|c|c|c|c|c|c|c|c|c|c|c|}
\hline \multirow{2}{*}{$\begin{array}{l}\text { Batch } \\
\text { No. }\end{array}$} & \multicolumn{3}{|c|}{ Zero-order Kinetics } & \multicolumn{3}{|c|}{ First-order kinetics } & \multicolumn{3}{|c|}{ Higuchi model } & \multicolumn{3}{|c|}{ Korsmeyer-Peppas model } \\
\hline & Intercept & $\mathbf{R}^{2}$ & $\begin{array}{l}\text { K } \\
\left(\mathrm{mg} \cdot h r^{-1}\right)\end{array}$ & Intercept & $\mathbf{R}^{2}$ & $\begin{array}{l}\mathrm{K} \\
\left(\mathrm{hr}^{-1}\right)\end{array}$ & Intercept & $\mathbf{R}^{2}$ & $\begin{array}{l}\text { K } \\
\left(\mathrm{mg}^{-1 / 2}\right)\end{array}$ & Intercept & $\mathbf{R}^{2}$ & $\mathbf{N}$ \\
\hline A1 & 11.378 & 0.9774 & 7.8487 & 2.1665 & 0.892 & 0.123 & 19.1 & 0.988 & 33.824 & 1.2743 & 0.9909 & 0.6674 \\
\hline A2 & 14.704 & 0.9596 & 7.5999 & 2.1507 & 0.8672 & 0.1243 & 13.213 & 0.9929 & 32.223 & 1.3287 & 0.991 & 0.6194 \\
\hline A3 & 19.801 & 0.9322 & 7.5142 & 2.1563 & 0.9083 & 0.1424 & 5.1759 & 0.9951 & 30.963 & 1.4219 & 0.9941 & 0.546 \\
\hline A4 & 9.4577 & 0.9814 & 7.4054 & 2.0764 & 0.9561 & 0.864 & 19.857 & 0.984 & 32.099 & 1.2236 & 0.9882 & 0.6849 \\
\hline A5 & 12.794 & 0.9697 & 7.5184 & 2.0962 & 0.9358 & 0.1023 & 15.502 & 0.9904 & 32.096 & 1.2959 & 0.9933 & 0.6317 \\
\hline A6 & 17.413 & 0.9473 & 7.2576 & 2.0755 & 0.9425 & 0.1059 & 7.2417 & 0.995 & 30.065 & 1.3854 & 0.9954 & 0.5571 \\
\hline A7 & 7.2885 & 0.9806 & 6.6038 & 2.0243 & 0.99 & 0.0587 & 19.971 & 0.991 & 29.044 & 1.1068 & 0.9961 & 0.7532 \\
\hline A8 & 8.569 & 0.9807 & 6.972 & 2.0399 & 0.9823 & 0.0693 & 19.603 & 0.9917 & 30.444 & 1.1612 & 0.9964 & 0.726 \\
\hline A9 & 10.504 & 0.9713 & 7.1004 & 2.0423 & 0.9779 & 0.0762 & 16.943 & 0.9799 & 30.555 & 1.2407 & 0.9836 & 0.6569 \\
\hline
\end{tabular}


Table 4: Summary of ANOVA results for response surface model

\begin{tabular}{|c|c|c|c|c|c|c|}
\hline Parameter & Sum of Squares & Degree of freedom & Mean square & F value & $\begin{array}{l}\text { p value } \\
\text { Prob. }>\text { F }\end{array}$ & Remark \\
\hline \multicolumn{7}{|c|}{ Percentage drug release $(1 \mathrm{~h})$} \\
\hline \multicolumn{7}{|c|}{ Percentage drug release (6 h) } \\
\hline \multicolumn{6}{|c|}{ Percentage drug release (12 h) } & Significant \\
\hline Quadratic model & 339.94 & 5 & 67.99 & 133.88 & 0.001 & Significant \\
\hline
\end{tabular}
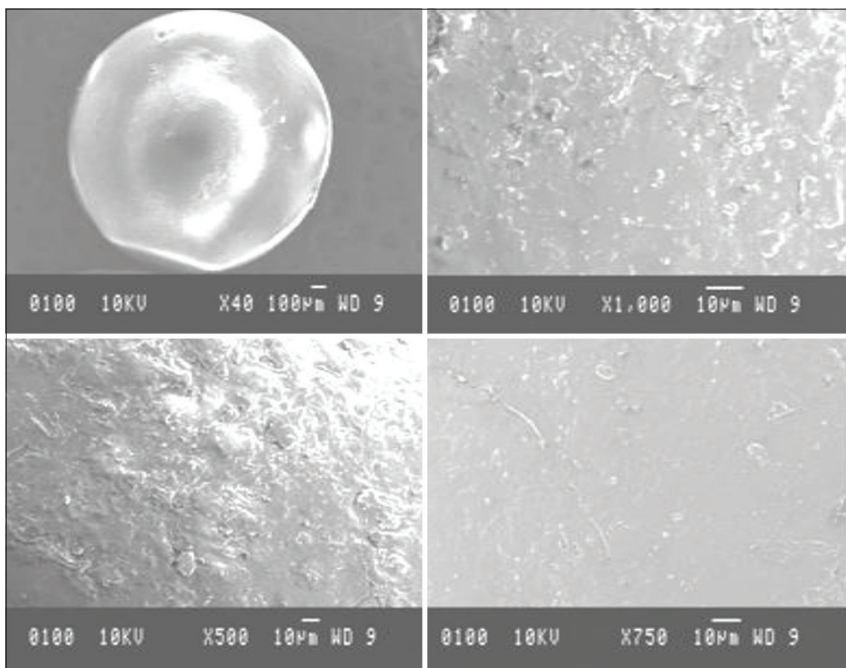

Fig. 5: Scanning electron microscope photographs at different magnification

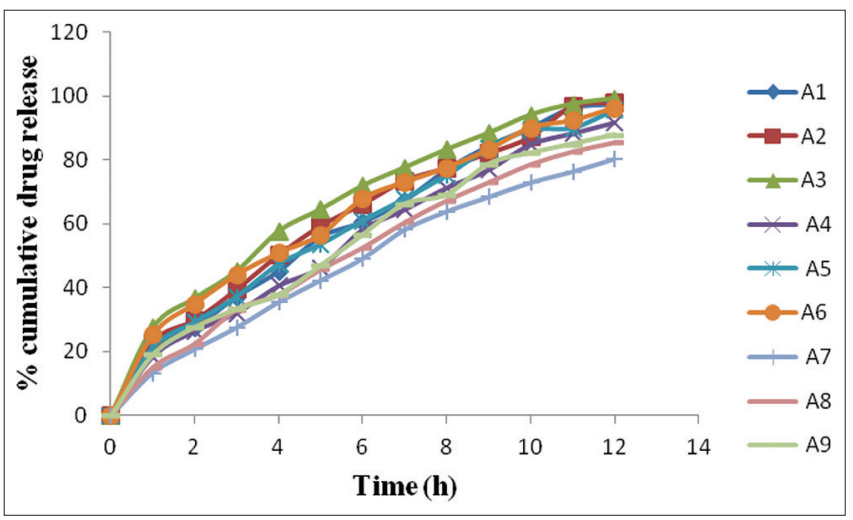

Fig. 6: Zero-order plot for formulation Batch A1 - A9

Surface Quadratic Model (suggested by software) is depicted in Table 4. The $\mathrm{p}$ values obtained is $<0.05$. This clearly indicates the significance of the model terms. Table 5 shows statistical dispersion analysis for all responses. The predicted and adjusted $\mathrm{R}^{2}$ value is fairly consistent. A desirable signal-to-noise ratio ( $>4)$ was measured, which indicates passable signal. Model can thus be utilized to traverse through the design space.

Fig. 10 shows surface plot for the drug release in 1, 6, and $12 \mathrm{~h}$. From the plot, it is evident that quantity of Gelucire $43 / 01$ has a substantial effect on the drug release. The drug release is inversely proportional to the level of release retardant Gelucire 43/01. On analyzing the dissolution study result, initial burst release was minimized with the increase in the amount of Gelucire 43/01 and the overall drug release was sustained for $12 \mathrm{~h}$. High hydrophobicity of Gelucire 43/01 could be the reason for this sustained release.

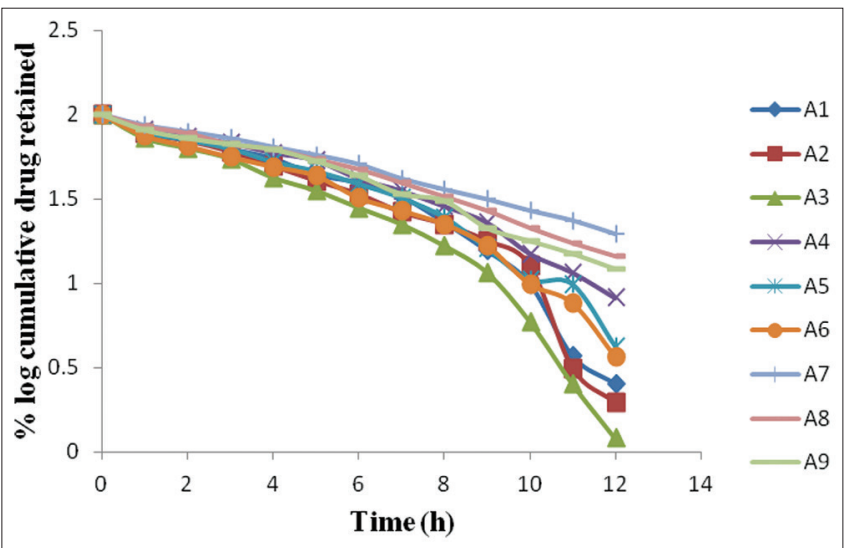

Fig. 7: First-order plot for formulation Batch A1 - A9

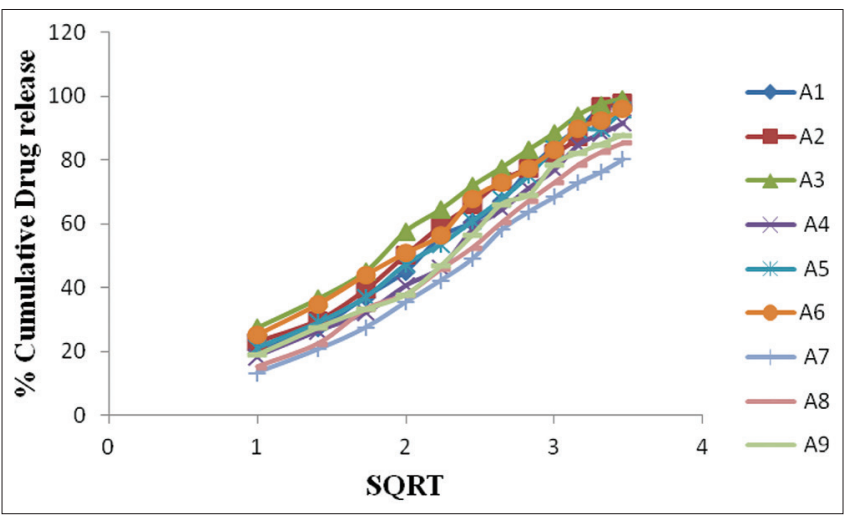

Fig. 8: Higuchi plot for formulation Batch A1 - A9

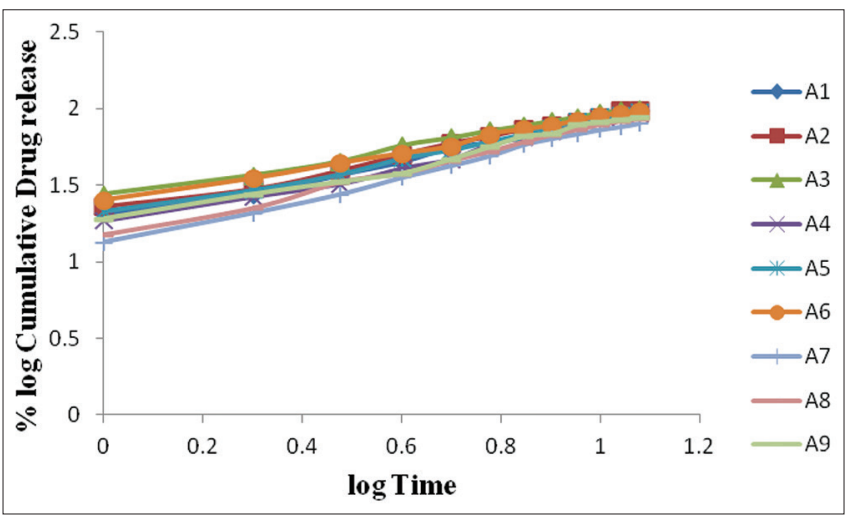

Fig. 9: Korsmeyer Peppas plot for formulation Batch A1 - A9

On the contrary, increase in the amount of Tween 20 maximized the drug release. When combining these independent variables, that is, 


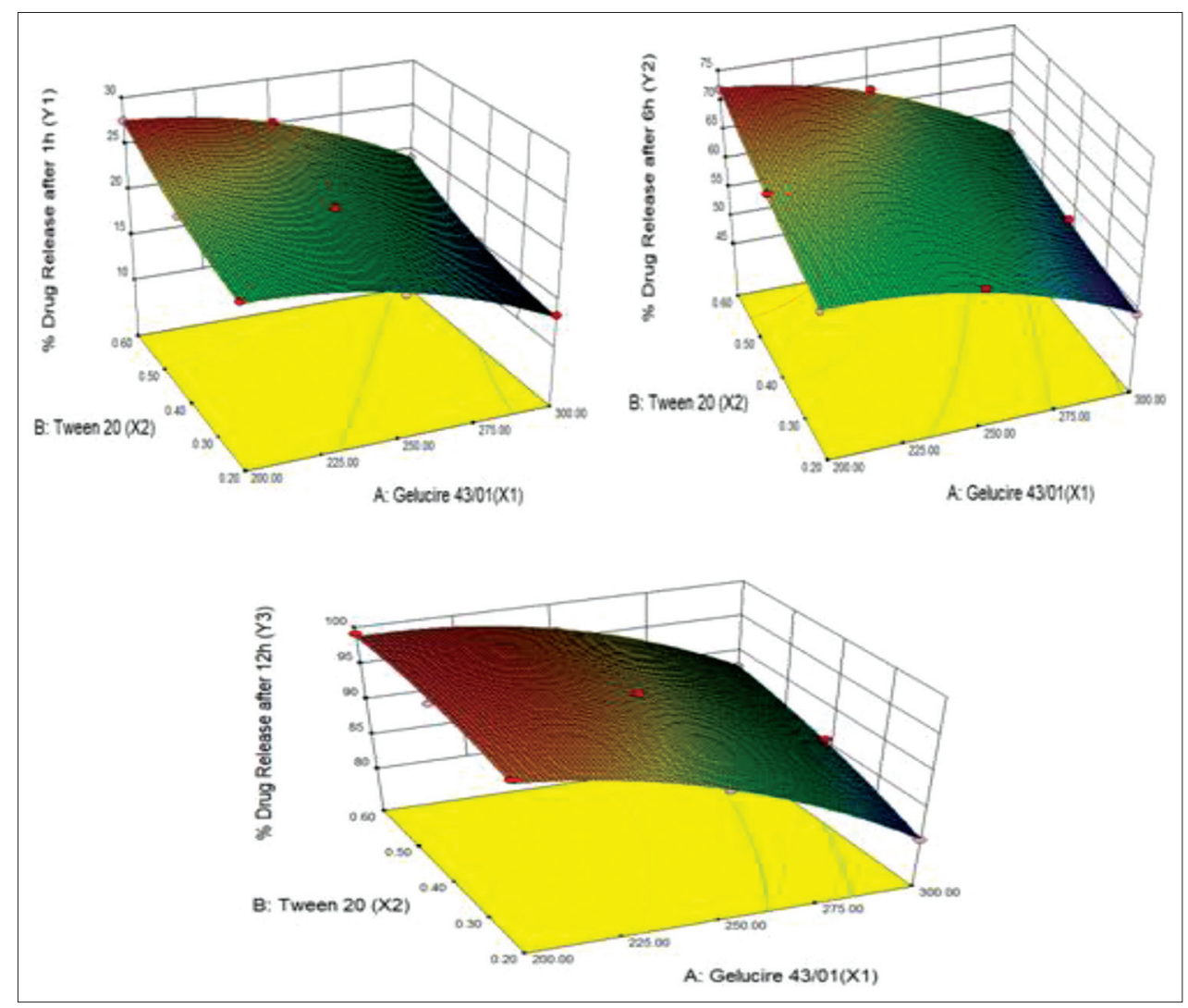

Fig. 10: 3D Response surface plots of $\mathrm{X} 1$ and $\mathrm{X} 2$ for responses $\mathrm{Y} 1, \mathrm{Y} 2$, and $\mathrm{Y} 3$

Table 5: Summary of statistical parameters for the responses

\begin{tabular}{llll}
\hline Parameter & \multicolumn{3}{l}{ Average drug release } \\
\cline { 2 - 4 } & $\mathbf{1} \mathbf{h}$ & $\mathbf{6 ~ h}$ & $\mathbf{1 2} \mathbf{~ h}$ \\
\hline Mean & 20.44 & 60.5 & 92.48 \\
$\mathrm{SD}$ & 0.28 & 0.85 & 0.71 \\
$\mathrm{CV} \%$ & 1.38 & 1.41 & 0.77 \\
$\mathrm{R}^{2}$ & 0.9986 & 0.995 & 0.9955 \\
Adjusted R $^{2}$ & 0.9961 & 0.9865 & 0.9881 \\
Predicted $\mathrm{R}^{2}$ & 0.9863 & 0.9624 & 0.9535 \\
Adequate precision & 62.229 & 32.669 & 31.393 \\
\hline
\end{tabular}

Tween 20 as solubility enhancement or drug loading agent and Gelucire $43 / 01$ with its hydrophobicity provided sufficient buoyancy to the beads to sustain for $12 \mathrm{~h}$.

The results can be correlated with the generated regression equations (A: Gelucire 43/01; B: Tween 20). The regression equation (Y1, Y2, and Y3) coefficients indicated that (A: Gelucire 43/01) had more pronounced negative effect and (B: Tween 20) indicated positive effect on drug release in 1,6 , and $12 \mathrm{~h}$.

Regression equations of the employed quadratic model:

Y1 - \% drug release after $1 \mathrm{~h}=21.07-3.95 \mathrm{~A}+3.20 \mathrm{~B}-0.29 \mathrm{AB}-1.88 \mathrm{~A}^{2}+0.93 \mathrm{~B}^{2}$ Y2 -- \% drug release after $6 \mathrm{~h}=62.10-6.80 \mathrm{~A}+4.55 \mathrm{~B}-1.10 \mathrm{AB}-3.19 \mathrm{~A}^{2}+0.79 \mathrm{~B}^{2}$ $\mathrm{Y} 2--\%$ drug release after $12 \mathrm{~h}=95.25-6.82 \mathrm{~A}+2.27 \mathrm{~B}+1.42 \mathrm{AB}-3.20 \mathrm{~A}^{2}-0.94 \mathrm{~B}^{2}$

The desirability method was used under the numeric optimization function to identify optimal formulation. By applying constraints to independent and dependent variables, an optimal formulation was achieved. The range of drug releases was set to a minimum of independent variables in 1, 6, and $12 \mathrm{~h}$. The highest desirability solution
( $\mathrm{n}=0.556$ ) was given by the design expert. The formulations optimized (batch A10) for the responses were developed and evaluated. The results obtained from the 1, 6, and $12 \mathrm{~h}$ (batch A 10) drug releases shown in Table 6. Numerical optimization results for batch A10 in Table 6 shows consistency in the experimental and theoretical values of drug release in 1,6 , and $12 \mathrm{~h}$. Higuchi equation for the optimized formulations was also found to be 0.9962 and desirability, that is, $\mathrm{n}=0.692$ which was also in near proximity suggested by numerical optimization.

\section{Comparison with marketed formulation}

The in vitro cumulative drug release of optimize formulation (A10) and marketed formulation compared show in Fig. 11. Marketed formulation (CONV) followed first-order kinetics and almost $96.28 \%$ drug released within $6 \mathrm{~h}$.

\section{CONCLUSION}

The present research can be concluded, Gelucire based floating beads formulation have been prepared and characterized using sparingly water-soluble drug. Beads were prepared using melt solidification method, by applying $3^{2}$ factorial designs. An optimized formulation (batch A10) comprising Gelucire 43/01 (274 mg) and Tween 20(0.2\%) was identified using numerical optimization function by Design expert Software. It showed $15.68 \%, 53.75$, and $85.54 \%$ drug release in 1,6 , and $12 \mathrm{~h}$, respectively. As the amount of Gelucire 43/01 increases, the drug release rate decreased and as the concentration of Tween 20 increased, the drug release rate was increased, due to high solubility with ramipril. Optimized formulation (A10) compared with marketed formulation for drug release results show that Gelucire 43/01 can be consider as an effective carrier for the design of a gastroretentive multi-particulate drug delivery system of sparingly water-soluble antihypertensive drug like ramipril. The present investigation shows the in vitro drug release profiles but further investigations are required to know clinically relevant plasma profiles of the drug and then after commercialization of the proposed work. 
Table 6: Summary of numerical optimization and responses

\begin{tabular}{|c|c|c|c|c|c|c|c|c|}
\hline \multirow[t]{2}{*}{ Formulation code } & \multicolumn{2}{|c|}{ Variable level } & \multicolumn{3}{|c|}{ Predicted responses } & \multicolumn{3}{|c|}{ Observed responses } \\
\hline & X1-Gelucire 43/01 & X2-Tween 20 & Y1 & Y2 & Y3 & Y1 & Y2 & Y3 \\
\hline A10 & 274 & 0.2 & 16.547 & 54.716 & 87.194 & 15.686 & 53.754 & 85.541 \\
\hline
\end{tabular}

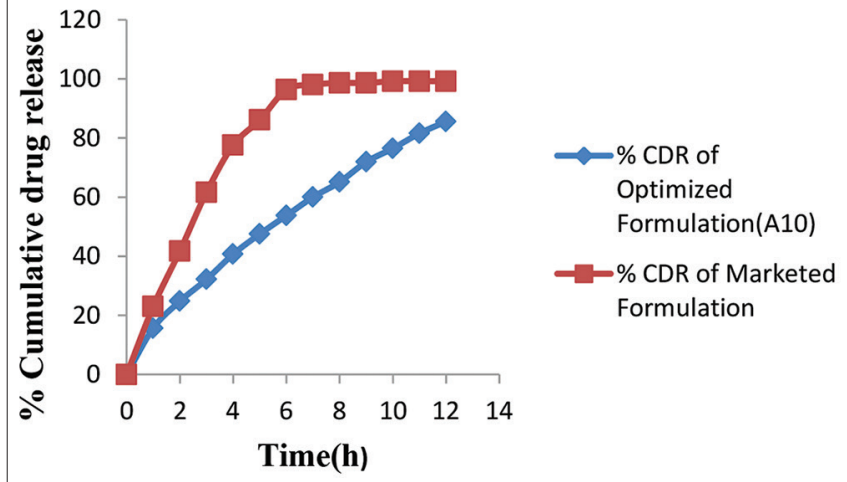

Fig. 11: Drug release profiles of optimized (A10) and marketed formulation

\section{ACKNOWLEDGMENTS}

The authors thankful to Dr. Anil Bhandari (JNVU, Jodhpur) for providing the laboratory facilities and his continue support throughout the research work. The authors acknowledge to Gattefosse India Pvt. Ltd., Mumbai, India, for providing gift sample of Gelucire 43/01, Gelucire 48/16, Gelucire 50/13, and Emcure pharmaceuticals Pvt. Ltd, Pune, India, for drug.

\section{AUTHOR CONTRIBUTIONS}

The writers are responsible for all aspects of the work to ensure that problems related to the accuracy or credibility of any component of the work are adequately reviewed and addressed.

\section{CONFLICTS OF INTEREST}

The research was conducted in the absence of any commercial or financial relationships that could be construed as a potential conflict of interest.

\section{AUTHOR FUNDING}

No particular grants from funding agencies in the public, commercial or non-profit sectors were obtained for this study.

\section{REFERENCES}

1. Sriamornsak P, Asavapichayont P, Nunthanid J, Luangtana-Anan M, Limmatvapirat S, Piriyaprasarth S. Wax incorporated emulsion gel beads of calcium pectinate for intragastric floating drug delivery. AAPS Pharm Sci Tech 2008;9:571-6.

2. Huanbutt K, Nernplod T, Akkaramongkolporn P, Sriamornsak P. Design of porous Eudragit L beads for floating drug delivery by wax removal technique. Asian J Pharm Sci 2017;12:227-34.

3. Singh BN, Kim KH. Floating drug delivery systems: An approach to oral controlled drug delivery via gastric retention. J Control Release 2000;63:235-9.

4. Rouge N, Allemann E, Gex-Fabry M, Balant L, Cole ET, Buri P, et al. Comparative pharmacokinetic studies of a floating multiple-unit capsule, a high density multiple unit capsules and an immediate-release tablet containing $25 \mathrm{mg}$ atenolol. Pharm Acta Helv 1998;73:81-7.

5. Streubel A, Siepmann J, Bodmeier R. Multiple unit Gastroretentive drug delivery: A new preparation method for low density microparticles. J Microencapsul 2003;20:329-47.

6. Goole J, Vanderbist F, Aruighi K. Development and evaluation of new multiple-unit levodopa sustained-release floating dosage forms. Int $\mathbf{J}$ Pharm 2007;334:35-41.

7. Sharma S, Pawar A. Low density multiparticulate system for pulsatile release of meloxicam. Int J Pharm 2006;313:150-8.

8. Santus G, Lazzarini G, Bottoni G, Sandefer EP, Page RC, Doll WJ, et al. An in vitro-in vivo investigation of oral bioadhesive controlled release furosemide formulations. Eur J Pharm Biopharm 1997;44:39-52.

9. Klausner EA, Lavy E, Friedman M, Hoffman A. Expandable gastroretentive dosage forms. J Control Release 2003;90:143-62.

10. Deshpande AA, Shah N, Rhodes CT, Malik W. Development of a novel controlled-release system for gastric retention. Pharm Res 1997;14:815-9.

11. Park K. Enzyme-digestible swelling as platforms for long-term oral drug delivery: Synthesis and characterization. Biomaterials 1988;9:435-41.

12. Gröning R, Berntgen M, Georgarakis M. Acyclovir serum concentrations following peroral administration of magnetic depot tablets and the influence of extracorporal magnets to control gastrointestinal transit. Eur J Pharm Biopharm 1998;46:285-91.

13. Chaturvedi S, Kumari P, Singh S, Agrawal VK. Approaches to increase the gastric residence time: Floating drug delivery systems-a review. Asian J Pharm Clin Res 2013;6:1-9.

14. Beneke CE, Viljoen AM, Hamman JH. Polymeric plant-derived excipients in drug delivery. Molecules 2009;14:2602-20.

15. Hauss DJ. Oral lipid-based formulations. Adv Drug Deliv Rev 2007:59:667-76

16. Jannin V, Musakhanian J, Marchaud D. Approaches for the development of solid and semi-solid lipid-based formulations. Adv Drug Deliv Rev 2008;60:734-46.

17. Singh S, Chakraborty S, Shukla D, Mishra B. Lipid-an emerging platform for oral delivery of drugs with poor bioavailability. Eur J Pharm Biopharm 2009;73:1-15.

18. Showkat HS, Pahuja S. Gelucire: A versatile formulation excipient. Int J Pharm Pharm Res 2017;10:55-73.

19. Meisel S, Shamiss A, Rosenthal T. Clinical pharmacokinetics of ramipril. Clin Pharmacokinet 1994;26:7-15.

20. Griensven JM, Schoemaker RC, Cohen AF, Luus HG, Grofe MS, Rothing HJ. Pharmacokinetics, pharmacodynamics and bioavailability of the ACE inhibitor ramipril. Eur J Clin Pharmacol 1995;47:513-8.

21. Frampton JE, Peters DH. Ramipril an updated review of its therapeutic use in essential hypertension and heart failure. Drugs 1995;49:440-66.

22. Bharkatiya M, Nema RK, Bhatnagar M. Development and characterization of transdermal patches of metoprolol tartrate. Asian J Pharm Clin Res 2010;3:130-4.

23. Jain SK, Gupta A. Development of Gelucire 43/01 beads of metformin for floating delivery. AAPS Pharm Sci Tech 2009;10:1128-36.

24. Mishra R, Dhole S. Lipid-based floating multiparticulate delivery system for bioavailability enhancement of berberine hydrochloride. J Appl Pharm Sci 2019;9:36-47.

25. Kamble RK, Chauhan CS, Kamble PR, Naruka PS. Formulation optimization of sustained release Resinate microcapsules of tramadol hydrochloride by using 32 factorial design. Int J Pharm Phytopharmacol Res 2016;6:57-63.

26. Gouda R, Baishya H, Qing Z. Application of mathematical models in drug release kinetics of carbidopa and levodopa ER tablets. J Dev Drugs 2017;6:1-8. 